\title{
Estimation of flow rate and sizing of trickling filter in a recirculating aquaculture system
}

\section{MOHAMMAD TANVEER}

Received : 24.05.2017; Revised : 02.09.2017; Accepted : 18.09.2017

Author for Correspondence :

\section{MOHAMMAD TANVEER}

College of Fisheries

Engineering, Tamil Nadu

Fisheries University,

NAGAPATTINAM (T.N.) INDIA

Email : nobletanveer@gmail.

com
- ABSTRACT : In a recirculating aquaculture system (RAS), waste is generated from uneaten feed, fish faecal matter and organic debris from dead and dying organisms. These wastes generally decompose to produce mainly nitrogenous compounds in the form of ammonia, nitrite and nitrate. These nitrogenous compounds are particularly important in intensive RAS because of their toxicity to culture organisms. Therefore, removal of these compounds is very much necessary for successful operation of RAS. Adsorption, ion exchange and biological filtration are the three major available options for removal of nitrogenous wastes. In the first two options, frequent regeneration of media is required which usually increases the cost of the operation. Therefore, in the present study biological filtration has been chosen an option for aquaculture wastewater treatment. In the present study proper sizing of biofilter based on mass balance approach has been presented which is of critical importance to the successful design of any recirculation system.

- KEY WORDS : Recirculation system, Nitrogenous compounds, Biological filtration

-HOW TO CITE THIS PAPER : Tanveer, Mohammad (2017). Estimation of flow rate and sizing of trickling filter in a recirculating aquaculture system. Internat. J. Agric. Engg., 10(2) : 577-580, DOI: 10.15740/HAS/IJAE/10.2/577-580. 